\title{
The spatial structure of the dayside ionospheric trough
}

\author{
S. E. Pryse, L. Kersley, M. J. Williams, I. K. Walker \\ Department of Physics, University of Wales, Aberystwyth, Ceredigion, SY23 3BZ, UK \\ Received: 22 September 1997 / Revised: 19 January 1998 / Accepted: 21 January 1998
}

\begin{abstract}
Tomographic imaging provides a powerful technique for obtaining images of the spatial distribution of ionospheric electron density at polar latitudes. The method, which involves monitoring radio transmissions from the Navy Navigation Satellite System at a meridional chain of ground receivers, has particular potential for complementing temporal measurements by other observing techniques such as the EISCAT incoherent-scatter radar facility. Tomographic reconstructions are presented here from a two-week campaign in November 1995 that show large-scale structuring of the polar ionosphere. Measurements by the EISCAT radar confirm the authenticity of the technique and provide additional information of the plasma electron and ion temperatures. The dayside trough, persistently observed at high latitudes during a geomagnetically quiet period but migrating to lower latitudes with increasing activity, is discussed in relationship to the pattern of the polarcap convection.
\end{abstract}

Key words. Ionosphere-magnetosphere interactions · Polar ionosphere $\cdot$ Radio science $\cdot$ Ionospheric propagation

\section{Introduction}

Tomographic imaging of the ionosphere was proposed some ten years ago (Austen et al., 1986). During the decade that followed considerable effort has been directed by the international community into building on this theoretical proposition to establish the technique as an ionospheric diagnostic method. Studies have been carried out to assess the experimental implementation of the method, for example Kersley and Pryse (1994).

Correspondence to: S. E. Pryse
Reconstruction algorithms suitable for the application have also been developed, several of which are discussed by Raymund (1995). The European Incoherent Scatter radar facility (EISCAT) has played a crucial role in the development of ionospheric tomography, in providing independent verification of tomographic images. An overview of this important role is given by Walker et al. (1996). Comparisons of tomographic reconstructions of ionospheric plasma distribution and EISCAT observations have been used to investigate several aspects of the technique. For example, they have confirmed the ability of tomography to image latitudinally narrow features, such as a deep trough and associated boundary blob (Mitchell et al., 1995); have enabled the investigation of the ability of the reconstruction process to locate correctly the ionisation layer peak (Mitchell et al., 1997a); have allowed the assessment of the effect of number of ground receivers on an image (Mitchell et al., 1997b); and have enabled initial developments towards three-dimensional imaging of the ionosphere (Mitchell et al., 1997c).

The success of such comparisons has resulted in a new ionospheric imaging technique that can now be used with confidence to yield the spatial plasma distribution over an extended region of the ionosphere. The method is now ready to be used to complement measurements by other ionospheric observing instruments, like the EISCAT and EISCAT Svalbard radars in the northern auroral and polar zones. Results are presented in this paper from a 2-week campaign in late November 1995, near solar minimum. Geomagnetic conditions for most of the campaign were extremely quiet. However, towards the end of the campaign there was a dramatic increase in activity. The focus of the results presented in this paper is the ionisation trough, consistently seen throughout the period of observations. During the night-time the feature constituted the wellstudied mid-latitude trough but at earlier times at the highest latitudes it was the less frequently observed trough on the dayside. 
The mid-latitude trough, reviewed by Moffett and Quegan (1983) and Roger et al. (1992), has been observed over several decades using various techniques. The feature separates the relatively well behaved, solar-controlled, mid-latitude ionosphere from the less predictable auroral region. The trough behaviour is well established, in particular the motion of the feature to lower latitudes during the night and rapid retreat at dawn. For example, a study by Collis and Häggström (1988) using an extensive set of EISCAT observations from solar minimum indicated the premidnight trough minimum to be essentially located in a region $1-2^{\circ}$ wide defined on the equatorward side by the reversal from westward convecting to corotating flow. In contrast, the dayside trough, occurring at higher latitudes, has not been so extensively studied, a likely consequence of the lack of ionospheric observations at the more inhospitable geographical locations. Whalen (1987, 1989) reports observations of the winter trough, based on measurements by ground-based ionospheric sounders during the International Geophysical Year, in December 1958 at solar maximum. These revealed a longitudinal dependence of the trough attributed to the offset of the geomagnetic co-ordinate system in which the high-latitude convection pattern resides from the geographic co-ordinates of the solar-terrestrial frame. Whalen (1989) proposed that the trough occurred in regions where sunward convective transport could displace high-density daytime plasma with low-density plasma from the nightside. This argument was used by Mallis and Essex (1993) to explain the occurrence of daytime troughs in TEC measurements in the southern hemisphere. Sojka et al. (1985) showed that the Utah State Model could predict the existence of a pronounced winter dayside trough in both hemispheres at solar maximum and low geomagnetic activity. This trough was also attributed to the offset between the geomagnetic and geographic co-ordinate systems and was the consequence of the solar zenith angles in the auroral oval being larger when the magnetic pole is on the anti-sunward side of the geographic pole. Trough observations under quiet geomagnetic conditions were included in the study of Tulunay and Grebowsky (1978) in which a midday trough was seen to reside near the shell $L=9$. Observations of high-latitude dayside troughs were also reported by Evans et al. (1983) and Holt et al. (1984). These observations were made during active magnetic conditions when the trough had migrated to lower latitudes. The mechanism cited in these cases was related to intense electric fields that caused heating and associated erosion of plasma density.

The results presented in this current paper show a nightside mid-latitude trough behaviour that conforms with previous observations. They also give new information on the dayside trough during an extended period of geomagnetically quiet conditions and at the time of a dramatic increase in magnetic activity.

\section{Experiment}

Radio signals from the satellites in the former Navy Navigation Satellite System (NNSS) were used for the tomographic observations. The satellites, in polar orbits at a height of about $1100 \mathrm{~km}$, transmit coherent signals at 150 and $400 \mathrm{MHz}$. The signals were received at a series of ground stations aligned in a chain along a line of longitude. In this way measurements were made of the Total Electron Content (TEC) along a large number of intersecting satellite-to-receiver ray paths. Inversion of the data gave an image of the electron density distribution over the region of ray-path intersections.

The reconstruction method used here consisted of two stages. The first step was to establish a background ionosphere suitable for the initialisation of the iterative second stage. This initial stage was based on the discrete inverse theory (DIT) method of Fremouw et al. (1994). In this approach the vertical ionisation profile is expressed in terms of a linear combination of empirical orthonormal functions (EOFs), derived in the present work from a set of more than 17000 Chapman profiles. The horizontal ionisation distribution is described by a Fourier expansion to which a one-dimensional red power-law is applied in keeping with previous observations of the spatial spectrum of ionospheric irregularities. When ionosonde data were available at appropriate time and location for the satellite pass, the measured electron density of the F-region peak was inserted as additional a priori information into the reconstruction process. The resulting background ionosphere obtained from this first stage was then used as the starting condition for the second stage, constituting an ART (Algebraic Reconstruction Technique) algorithm. This second stage was used essentially to reconstruct the detail in the horizontal distribution. The image grid extended over all satellite-to-receiver ray paths and had a resolution of $0.25^{\circ}$ latitude by $15 \mathrm{~km}$ altitude.

During the 2-week campaign from 15 to 30 November 1995 six receivers were set in a chain in Scandinavia at Ny-Ålesund, Longyearbyen, Tromsø, Kiruna, Lycksele and Uppsala (Fig. 1). A total of approximately 140 satellite passes were monitored simultaneously at three or more of the receiving sites. During many of these passes the EISCAT radar made co-ordinated observations whilst running either in the $\mathrm{CP} 3$ common programme mode or the SP-UK-TOMO special programme mode. In both of these modes of operation the radar performed north-to-south latitudinal scans in the meridian of Tromsø. For the former the scan was in the geomagnetic meridian and covered some $10^{\circ}$ latitude at F-region heights, centred above Troms $\varnothing$, over a cycle time of $30 \mathrm{~min}$. The TOMO routine, described in more detail by Heaton et al. (1995), observed to the south of Tromsø in the geographic meridian, covering from 62.5 to $69.5^{\circ}$ latitude in the $\mathrm{F}$ region in $20 \mathrm{~min}$, thus giving an improved horizontal resolution over the CP3 observations at the expense of smaller latitudinal coverage. 


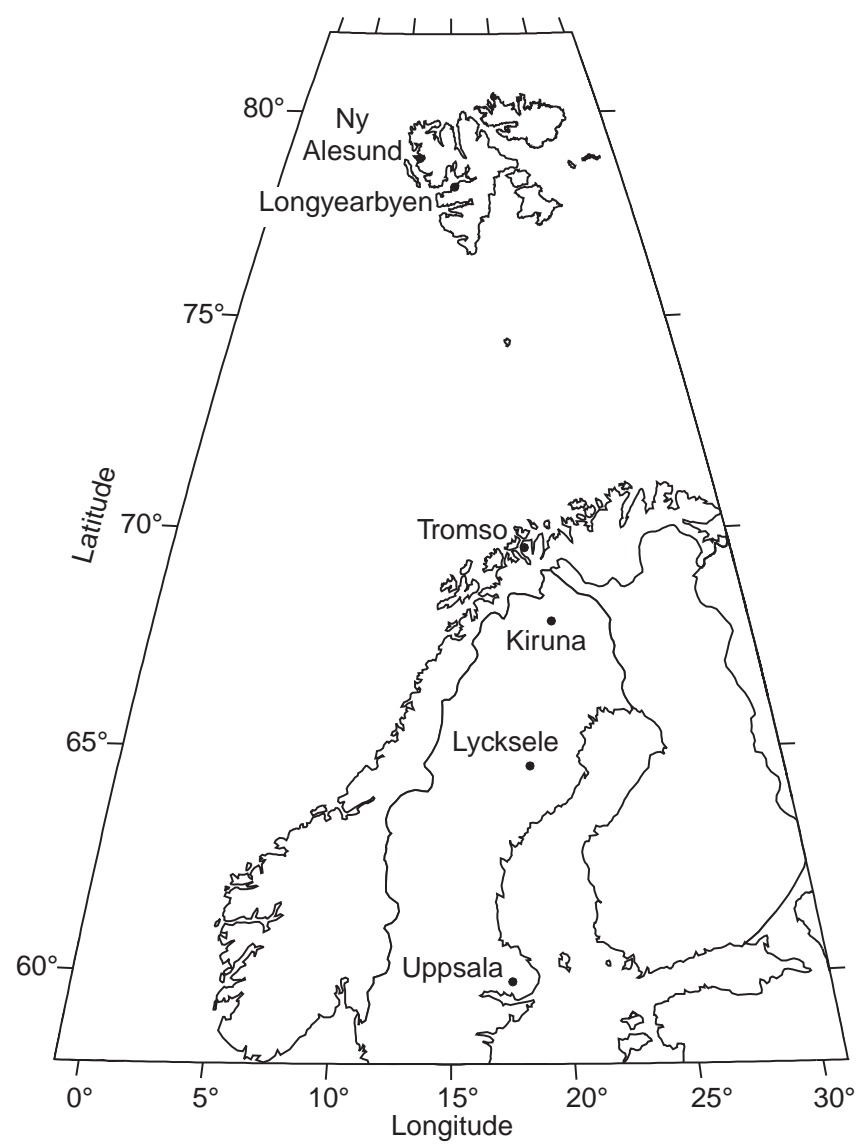

Fig. 1. Map showing the locations of the six receiving stations of the tomography chain

\section{Results}

For most of the period of the campaign, the WIND satellite was appropriately located in the solar wind to give values of the Interplanetary Magnetic Field (IMF). The measurements from 15 November (day-number 319 ) to 27 November (day-number 331) 1995, are shown in Fig. 2. The values have been smoothed over $45 \mathrm{~min}$ for presentational purposes. The data for the following day were not as reliable because the satellite had moved out of the solar wind. The graph shows little marked activity for most of the observational period, with the magnitude of $B$ (top panel) from day-number 319 to day-number 330 being generally less than $10 \mathrm{nT}$, and indeed hardly exceeding $5 \mathrm{nT}$ after the first three days. The bottom three panels show the corresponding $B_{x}, B_{y}$ and $B_{z}$ components. On 27 November at about 06:15 UT there was a dramatic change in the IMF, during which the magnitude of the field increased rapidly to reach a maximum of approximately $30 \mathrm{nT}$ near 12:00 UT. The detail of the IMF for this day is shown in Fig. 3 where the unsmoothed data is shown on an expanded time-scale. In addition to the trend in the increase in $B$, the plots show the variability in each of the components. The $B_{z}$ component initially increased negatively, reaching a minimum of some $-25 \mathrm{nT}$ at about 10:45 UT. It then reversed direction and main- tained its maximum value of about $24 \mathrm{nT}$ from around 11:40 to $12: 40$ UT. $B_{y}$ was large and positive, with a broad maximum of about $18 \mathrm{nT}$ and a variability of several nT. Thus, geomagnetic activity was extreme and showed significant variation. Similar conditions were reflected by the Kp index. Values for 15 to 26 November were generally low, and indeed those for 24 to 26 November averaged less than 1-. By contrast, for 27 November the three-hourly values throughout the day were $1-, 1,3,6+, 4-, 4-, 4-, 3+$, respectively. Activity was significantly reduced on the following day, but did not resume its extremely quiet pre-disturbance state. The following discussion firstly addresses observations made during the quiet period and then the dramatic changes that occurred as a consequence of the magnetic disturbance.

\subsection{Quiet geomagnetic conditions}

Figure 4 shows typical examples of images of the dayside ionosphere during the quiet period, on a

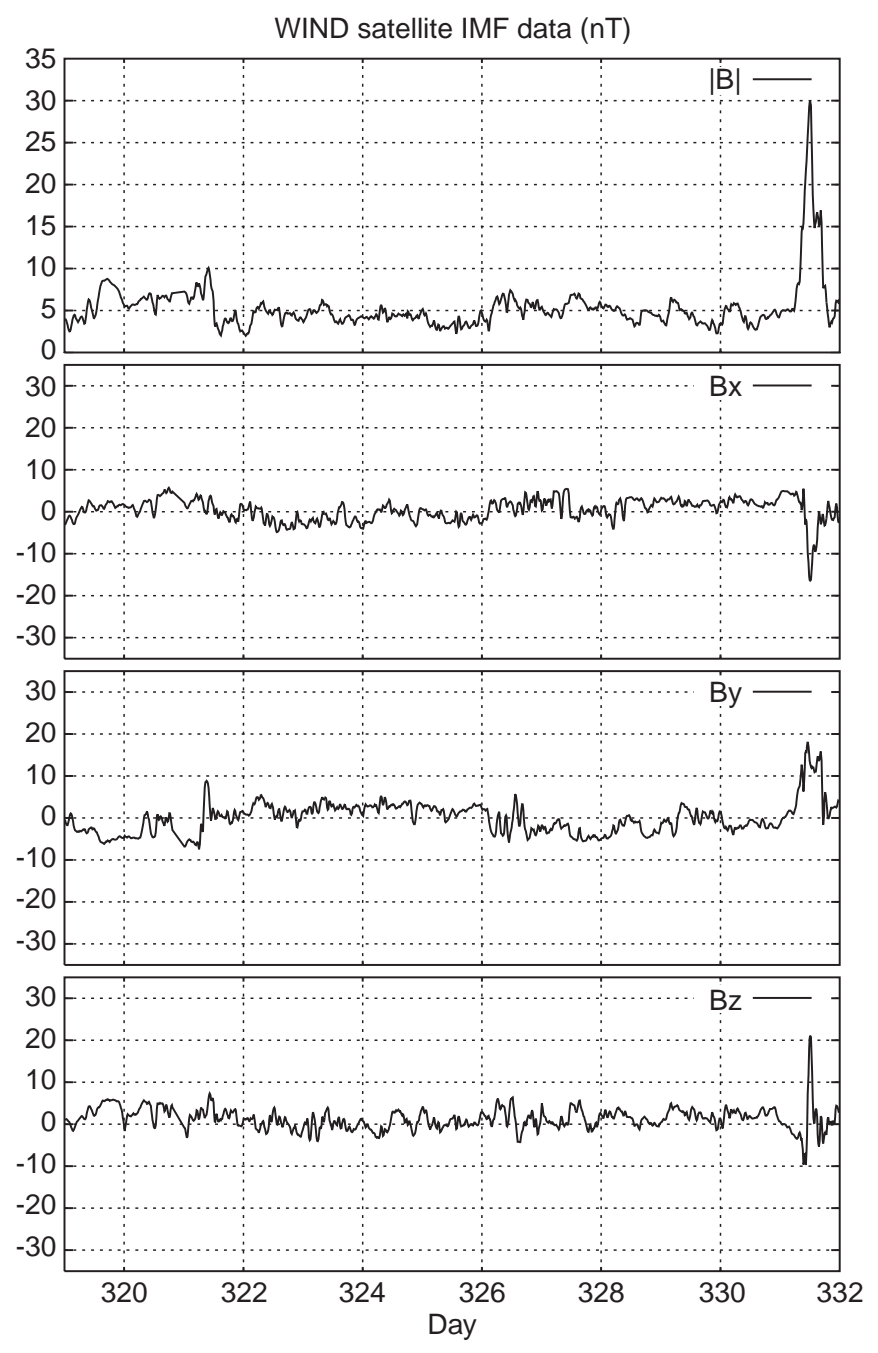

Fig. 2. The magnitude and components of the IMF measured by the WIND satellite from 15 November (day-number 319) to 27 November (day-number 331) 1995. The data have been smoothed over $45 \mathrm{~min}$ 

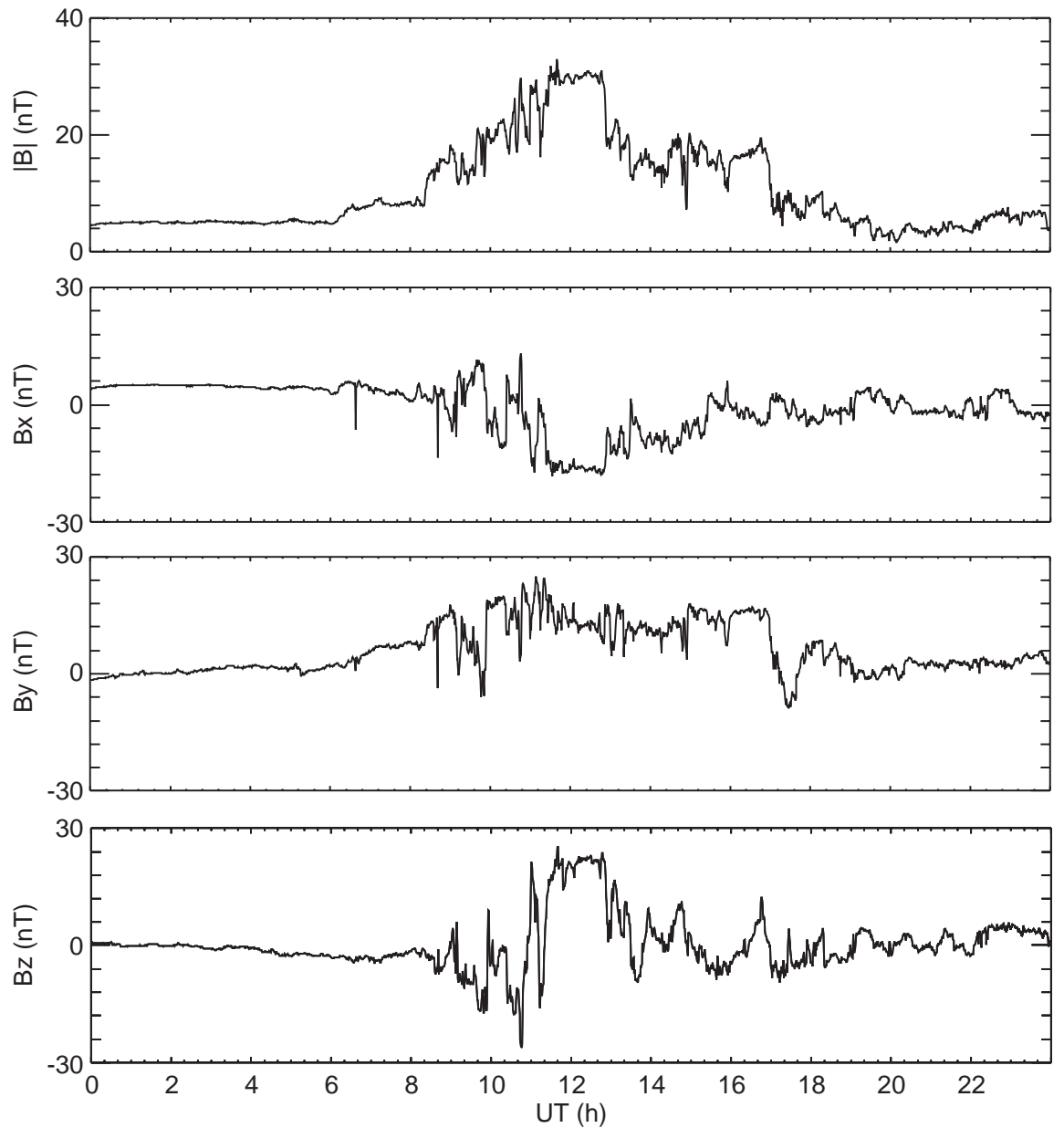

Fig. 3. The magnitude and components of the IMF measured by the WIND satellite on 27 November 1995 (day-number 331) height-versus-geographic-latitude grid. The upper two panels contain the tomographic reconstructions from two consecutive passes on 21 November 1995. It can be noted that $\mathrm{NmF} 2$ values from ionosondes at Uppsala, Lycksele and Kiruna were incorporated as additional information into the inversion process. The satellite in the first pass crossed a latitude of $70.0^{\circ} \mathrm{N}$ at $12: 51 \mathrm{UT}$. For the second, the crossing was at 14:02 UT. Both images show solar-produced ionisation at the lower latitudes with decreasing densities to the north ending in a clear trough and smaller-scale structuring at the northernmost latitudes. The densities of the later image are slightly reduced from those of the earlier one with the peak density at the trough minimum being $0.7 \times 10^{11} \mathrm{~m}^{-3}$ in comparison with $1.0 \times 10^{11} \mathrm{~m}^{-3}$. There has also been an apparent equatorward movement of the trough minimum, from a latitude of $76.0^{\circ} \mathrm{N}$ to $74.0^{\circ} \mathrm{N}$, during the $70 \mathrm{~min}$ separating the two plots. The electron densities from the corresponding EISCAT CP3 scans, shown in the lower panels, verify the reconstructions. The presence of the trough is confirmed though the coverage to the north is not sufficient in the CP3 mode to establish the position of the trough minimum. Corresponding electron temperature measurements by the radar (Fig. 5) yield relatively low values near the trough minimum and its equatorward edge, ruling out local soft-particle precip- itation as an important physical mechanism in this region.

Reconstructions from all passes monitored during the quiet period enabled the study of the average trough location. The squares joined by dashed lines on the geomagnetic latitude versus MLT polar plot of Fig. 6 show the average position of the trough minimum, obtained from data binned into hourly intervals of Universal Time. The standard deviation of each trough position, calculated if there were five or more passes in a bin, is shown by the arrows through the square. The two regions where no trough is indicated, between approximately 19:00 and 22:00 MLT, and 06:00 and 10:00 MLT, correspond to times when there were no suitable passes during the campaign. Superimposed on the plot is the IZMEM electric potential pattern (Papitashvili et al., 1994) for the mean IMF of the quiet-time observations, which gives an indication of the convection flow. The first point of note is the trough minimum in the premidnight to morning sector, located near the equatorward edge of the convection flow. This corresponds to the mid-latitude trough which has been widely observed over many years. The more pertinent observation for the current study is the dayside trough. Here the minimum maps into the region of sunward return flow of the dusk convection cell, which may, as suggested by Whalen (1989), be bringing plasma that 

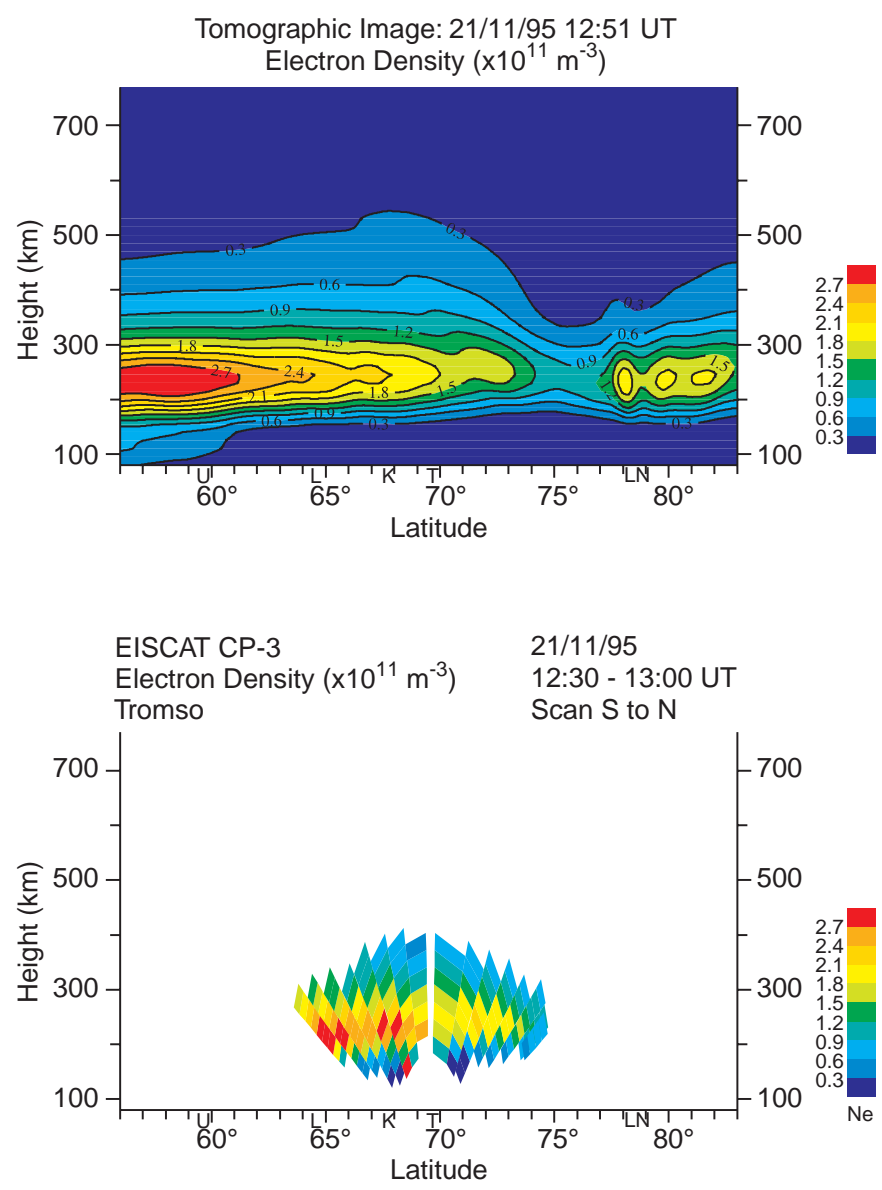

Fig. 4. Tomographic images from satellite passes at 12:51 and 14:02 UT on 21 November 1995 which are representative of those obtained under the quiet geomagnetic conditions (upper panels).

has been circulating in darkness into the higher densities of the dayside ionisation. It is also worth noting that the magnitudes of the standard deviation of the trough location in this time-sector are generally less than about $1^{\circ}$ latitude, so that the position is well defined.

\subsection{Disturbed geomagnetic conditions}

Four satellite passes were monitored on the afternoon of the disturbed day of 27 November 1995. The trajectories of these consecutive passes are shown by the straight lines in Fig. 7. The squares on each line give the location of the trough minimum, considerably lower in latitude than the points for the quiet period, shown on the figure for comparison. There is a progressive motion of the trough to lower latitudes during the course of the afternoon. Superimposed is the IZMEM electric potential contours for $B_{y}=15 \mathrm{nT}$ and $B_{z}=-25 \mathrm{nT}$, the instantaneous values of the field components when $B_{z}$ took its most extreme negative value. Whilst caution should be exercised in the application of this empirical model under such extreme conditions, the plot when compared with Fig. 6 suggests a marked rotational distortion of the convection throat region towards later hours.
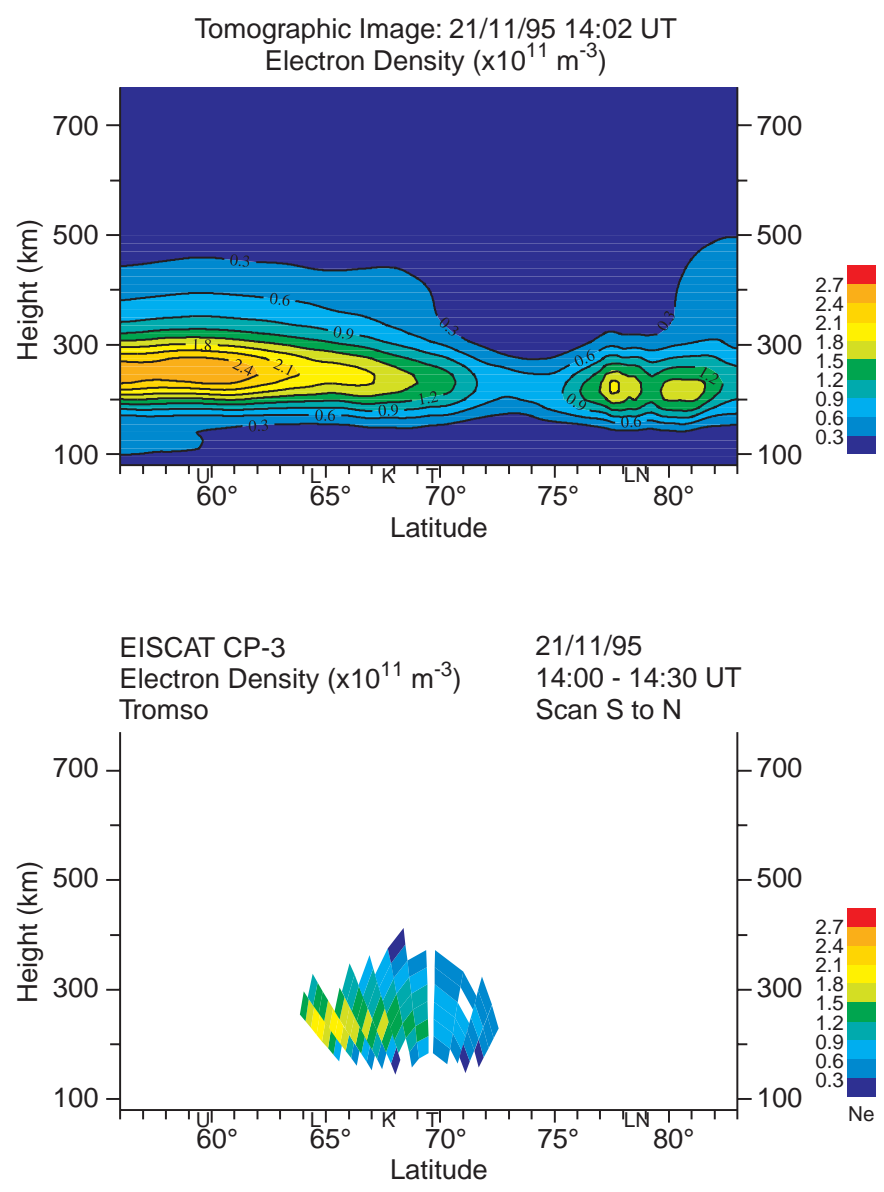

Corresponding electron densities measured by the EISCAT radar observing in the CP3 common programme mode for scans from 12:30 to 13:00 UT and 14:00 to 14:30 UT (lower panels)

The tomographic images from the four passes during this time are shown in Fig. 8. The plasma distribution of the first panel, for a satellite pass at 11:15 UT (Fig. 8a), shows a smooth, well-behaved mid-latitude ionosphere at the southernmost latitudes. The height of the layer peak in this region is approximately $275 \mathrm{~km}$. Towards the north, a density reduction culminates in a very shallow minimum near $71.5^{\circ}$ latitude which is followed by a slight increase in density. Of particular note in this plot is that the plasma in the northernmost region differs significantly from that at mid-latitudes in that densities are lower and the layer peak, near $325 \mathrm{~km}$, is higher.

The second panel (Fig. 8b), for a pass less than $1 \mathrm{~h}$ later, illustrates a clear density trough. In this case the larger plasma concentrations on either side of the lower densities result in a well-pronounced feature with a minimum at $69.5^{\circ}$. Peak densities in the region of midlatitude ionisation and in the enhancement to the north of the trough are essentially equal, with maximum values in excess of $4.5 \times 10^{11} \mathrm{~m}^{-3}$. The peak height of the ionisation remains approximately constant at about $275 \mathrm{~km}$ over the entire latitude range of the image. The similar nature of the ionisation in both the mid- and polar regions of the plot suggest that the plasma in both regimes could be of common origin. 

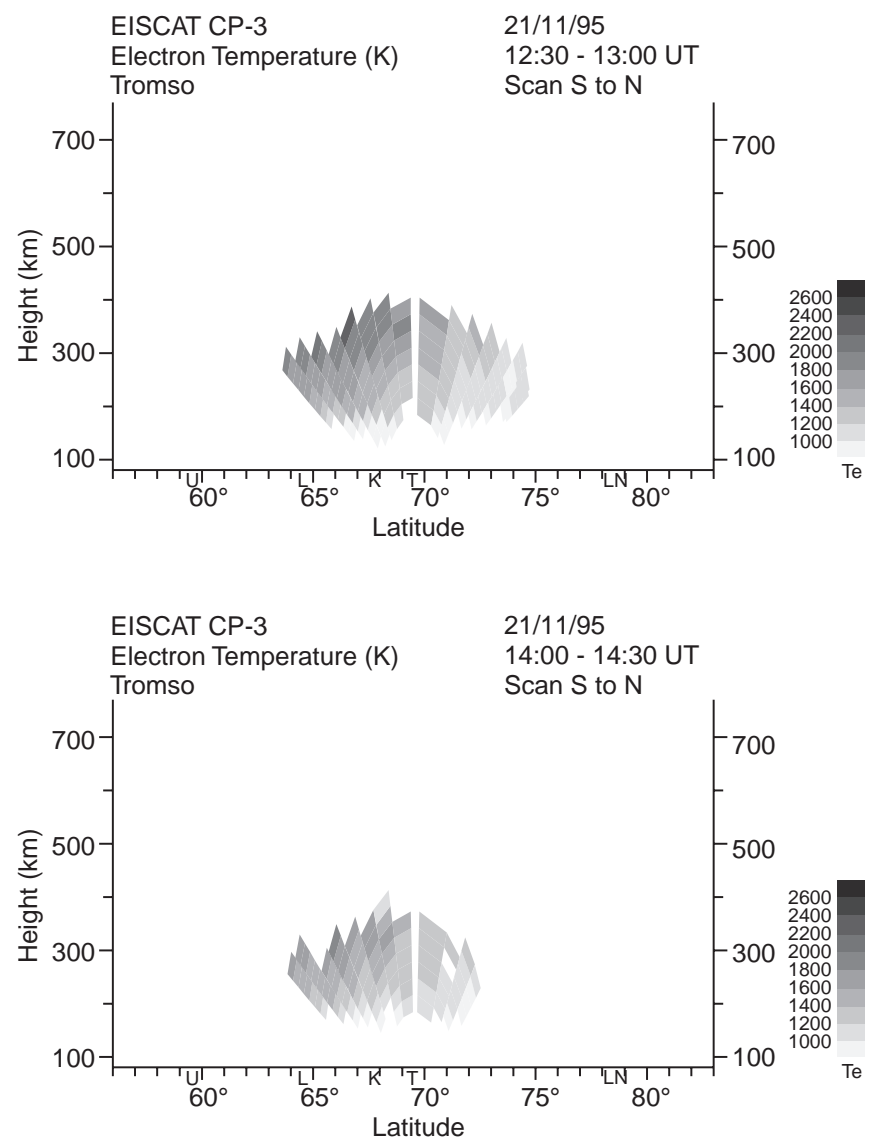

Fig. 5. Electron temperatures measured during EISCAT CP3 scans from 12:30 to 13:00 UT and 14:00 to 14:30 UT on 21 November 1995 corresponding to the electron densities in Fig. 4

The density distribution in the third panel (Fig. 8c), for a pass at 13:18 UT, again shows a trough, with its minimum at $68.5^{\circ}$ latitude. The peak densities of the photoionisation to the south again exceed $4.5 \times 10^{11} \mathrm{~m}^{-3}$, however the F-region values to the north are now reduced and reach values only slightly greater than $3.0 \times 10^{11} \mathrm{~m}^{-3}$. The peak height of the ionisation is constant over the range of the image. Thus, whilst in this case the F-region density values to the north are lower than those to the south, the peak height indicates some similarity in the character of the plasma over the latitudinal extent of the image. Enhanced Eregion densities in the northern part of the image suggest the occurrence of soft-particle precipitation in this latitude region with hardening of the particle energies between 77 and $80^{\circ} \mathrm{N}$.

The final panel for a pass at 15:05 UT (Fig. 8d) shows a very different ionosphere. The ionisation peak height in the mid-latitude region remains at $275 \mathrm{~km}$, but the densities are significantly reduced to a maximum of less than $3.0 \times 10^{11} \mathrm{~m}^{-3}$ as solar photoproduction declines. The character of the structured plasma to the north is in complete contrast to earlier reconstructions. With peak densities just exceeding $2.0 \times 10^{11} \mathrm{~m}^{-3}$ in the centre of an enhancement and a peak height above $300 \mathrm{~km}$, the structure suggests that the region is influenced by different processes to those operating at the

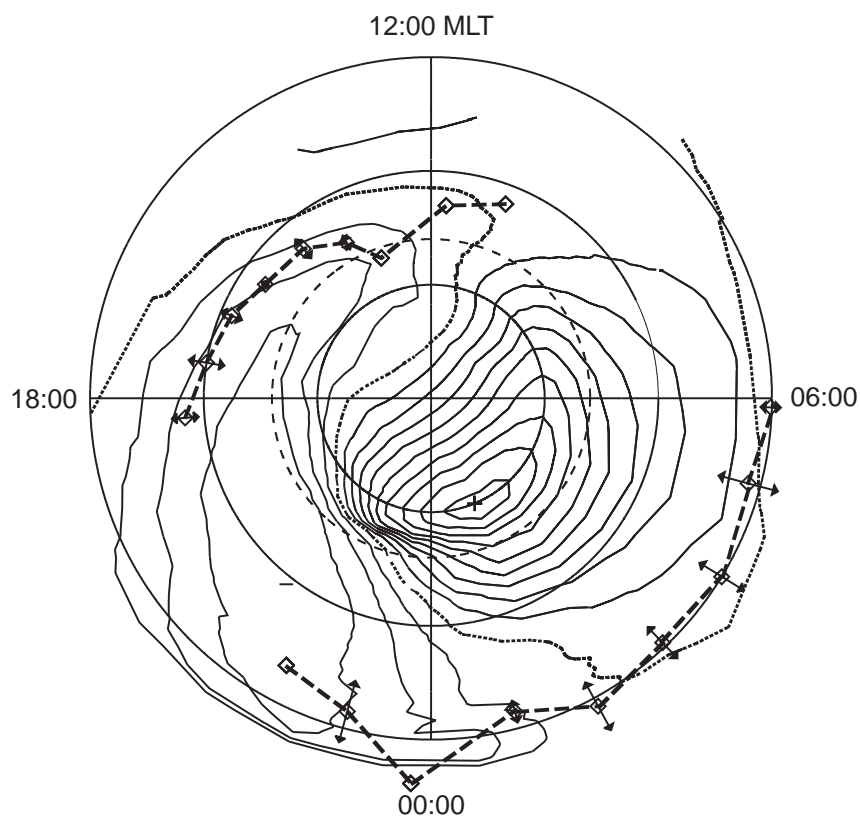

Fig. 6. Dial plot showing the average position of the postmidnight mid-latitude trough and the dayside trough during the quiet geomagnetic conditions as a function of corrected geomagnetic latitude $\left(60-90^{\circ} \mathrm{CGM}\right)$ and MLT. The squares indicate the location of the trough minimum and the arrows the associated standard deviation. Superimposed is the IZMEM electric potential contours at $5-\mathrm{kV}$ intervals for the mean IMF of the quiet period

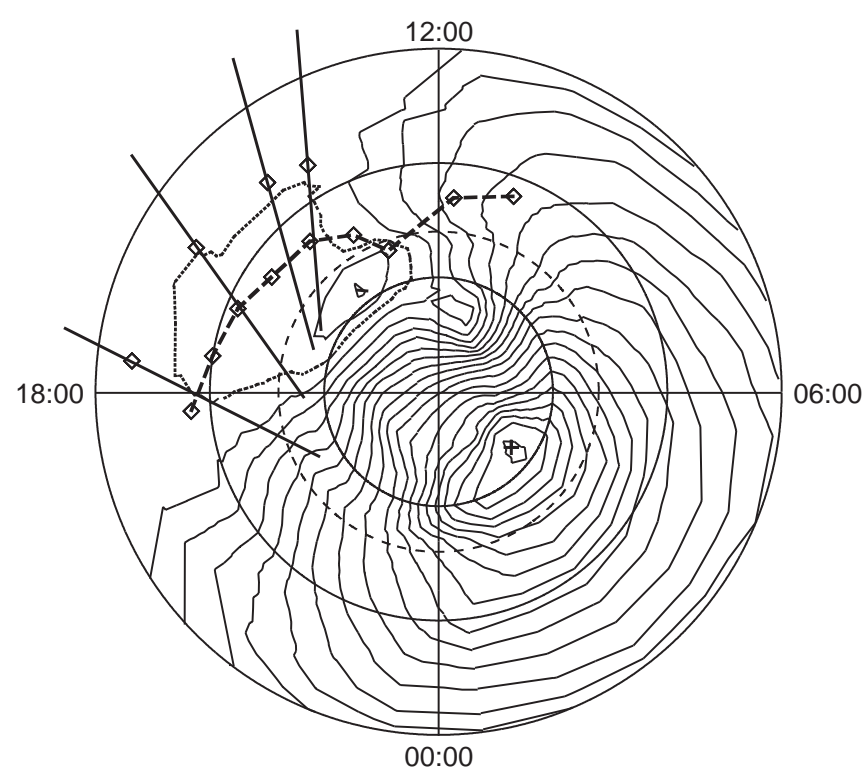

Fig. 7. Latitude $\left(60-90^{\circ} \mathrm{CGM}\right)$ versus MLT dial plot indicating the trajectories of the four satellite passes monitored consecutively on the afternoon of the geomagnetically disturbed day of 27 November 1995. The squares on the trajectories show the position of the trough minimum at the times of these passes. Also indicated is the mean position of the trough minimum under the quiet conditions, and superimposed is the IZMEM electric potential contours at $5-\mathrm{kV}$ intervals for the IMF at the time of the most extreme southward IMF

lower latitudes. Moreover, there is a very deep trough separating these two regimes of the ionosphere in which the peak densities fall to less than $0.5 \times 10^{11} \mathrm{~m}^{-3}$. In this 
case it is likely that the southern section of the image is coincident with corotating plasma at the equatorward edge of the high-latitude convection, while that further north intersects the dusk cell.

The EISCAT radar observed in the TOMO special programme mode on this day. Electron temperatures covering the times of the second and third passes are shown in Fig. 9. The first two images for scans starting at 11:40 and 12:00 UT (Fig. 9a and b) show a region of enhanced values in the northern region of the scans at F-region heights, indicating particle precipitation in keeping with the disturbed observing conditions. These plots span the time of the reconstruction of Fig. 8b. The location of the large electron temperatures suggests that the precipitation extended from at least the poleward wall of the trough, through the trough minimum to its equatorward gradient. The equatorward edge of the precipitation region is seen to have progressed steadily southwards in the following two scans (Fig. 9c and d), reaching the southern extreme of the field of view by the end of the scan starting at 12:40 UT. During the next three scans (Fig. 9e, f and g) high temperatures were measured over the entire field of view of the radar, confirming that precipitation was occurring within the trough minimum. The scan starting at 14:00 UT gave results in complete contrast to those earlier, with no clear signature of precipitation being apparent.

The ion temperatures observed by EISCAT showed no clear signature of activity from 11:40 to 14:00 UT. Typical observations from this time-interval are illustrated in Fig. 10a for the scan starting at 13:40 UT. However, the scan starting at 14:00 UT (Fig. 10b) showed the early stages of a dramatic localised enhancement in ion temperatures that resulted in erosion of plasma densities and the formation of a deep trough. The localised heating associated with this event is seen as a narrow ion temperature enhancement within the latitude band of $66.5-68.0^{\circ} \mathrm{N}$ in the plot of Fig. 10b. To the south there is a region lacking in data, a consequence of the signal-to-noise ratios being too low for the standard analysis because of extremely low densities. It is possible that the heating event had also covered this region but by the time the radar beam was observing at these elevations the densities were already too low for measurement. There is no evidence of increased ion temperatures in the following two scans (Fig. 10c and d), but there remains a lack of data in the southernmost region continuing to imply very low densities. It can be noted that the northern edge of the heating event was well defined, being at a latitude of $68^{\circ} \mathrm{N}$ in Fig. 10b. The abrupt boundary is also apparent in the following two
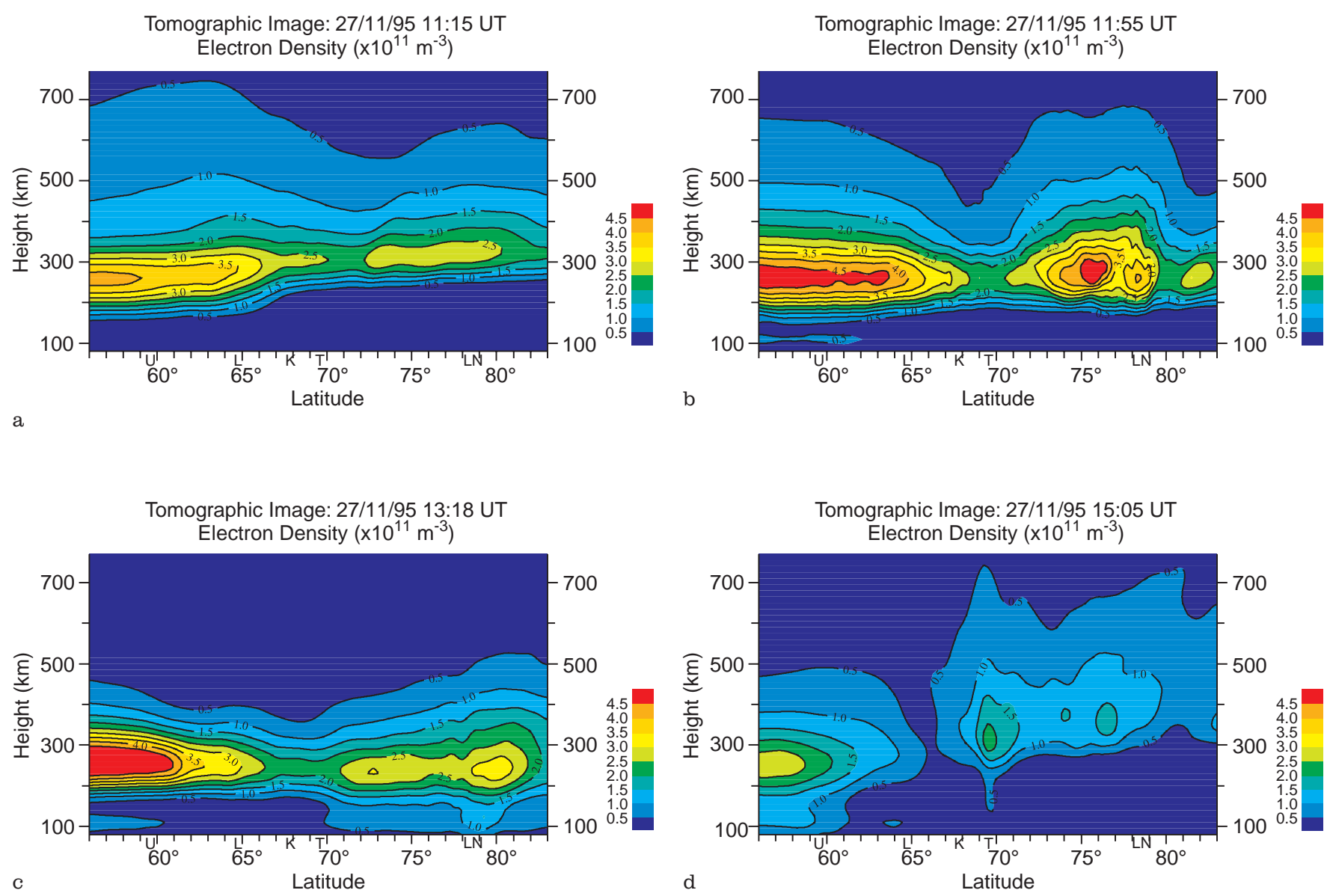

Fig. 8a-d. Tomographic reconstructions for the four satellite passes monitored on the afternoon of 27 November 1995, a for pass at 11:15 UT, b for pass at 11:55 UT, $\mathbf{c}$ for pass at 13:18 UT and $\mathbf{d}$ for pass at 15:05 UT 

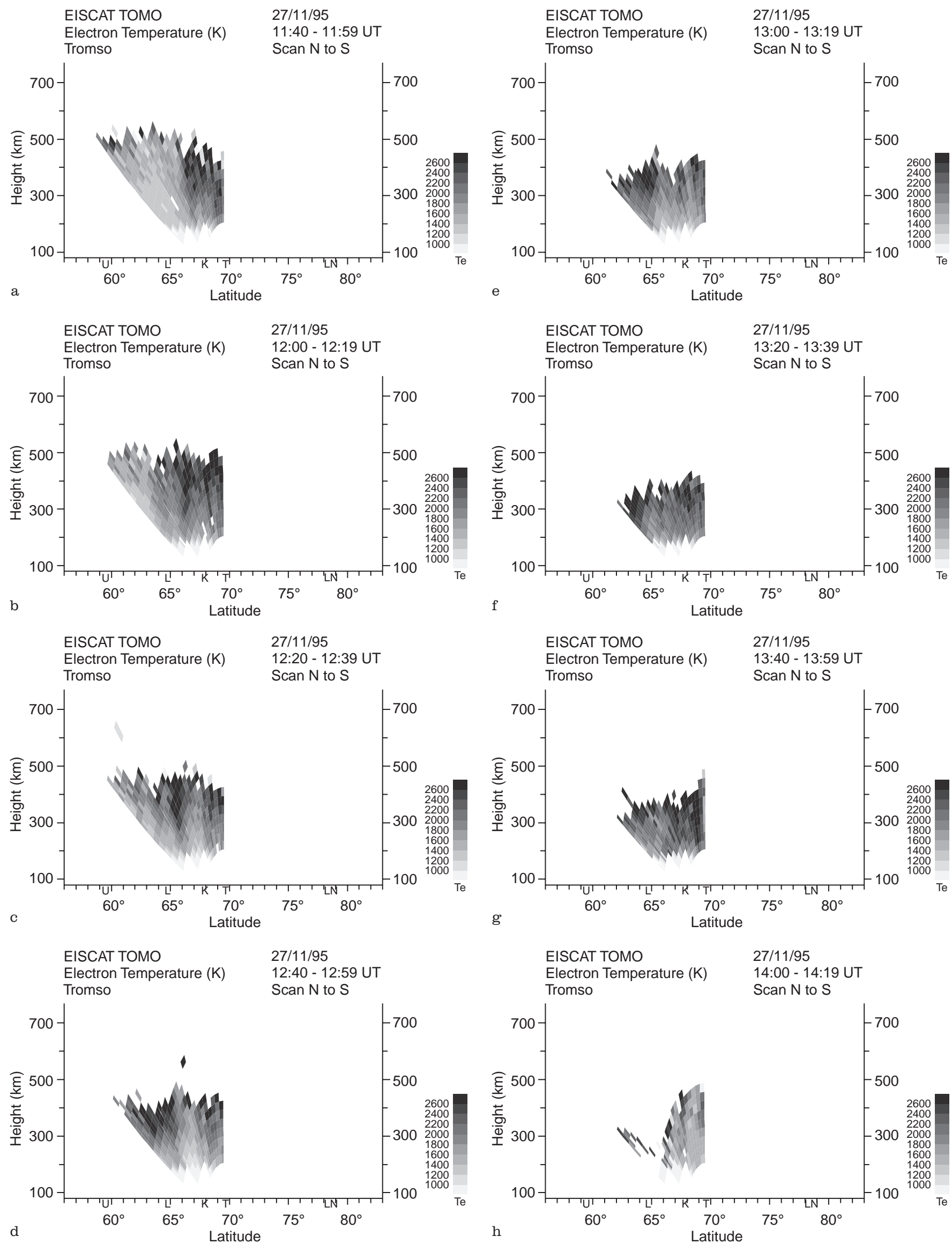

Fig. 9a-h. Electron temperatures measured by the EISCAT radar observing in the TOMO special programme mode for a series of scans between 11:40 and 14:20 UT on 27 November 1995 

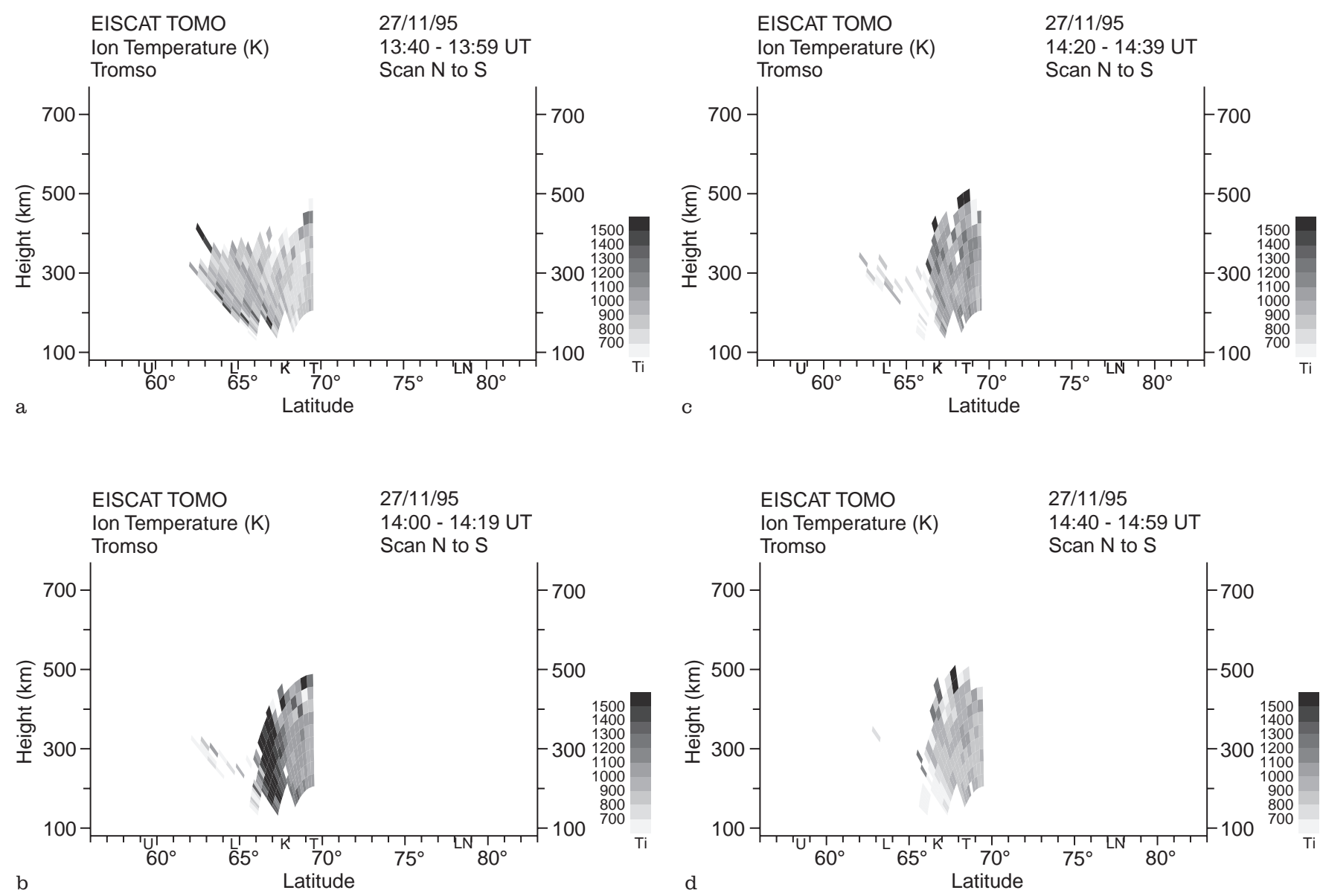

Fig. 10a-d. Ion temperatures measured by the EISCAT radar observing in the TOMO special programme mode for a series of scans between 13:40 and 15:00 UT on 27 November 1995

panels with the sharp transition between the region lacking in data and that with data. Close inspection shows a gradual equatorward motion of this boundary, reaching about $66.5^{\circ}$ latitude by the time of Fig. 10d. While the radar was unable to measure the low densities, the tomographic image of 15:05 UT confirms the low densities of the deep trough, with the $0.5 \times 10^{11} \mathrm{~m}^{-3}$ contour on the northern edge coinciding with the northern edge of the missing EISCAT data.

Only a few tomographic images were available for times subsequent to the magnetic disturbance. The two reconstructions available for late morning on 28 November (not shown) indicated that the trough had retracted to its pre-disturbance location.

\section{Discussion}

The tomographic data from the quiet geomagnetic period revealed a persistent dayside trough in the vicinity of the return flow of the dusk convection cell. The behaviour of this structure was repeatable from day to day, with the standard deviations in the mean position of the minimum density at the F-region peak being less than about one degree latitude. The corrected geomagnetic latitude of the minimum at 16:00 MLT was near $71^{\circ}$, in reasonable agreement with the equatorward edge of the winter afternoon troughs of Whalen (1989) under moderately quiet conditions at solar maximum. Whalen (1989) suggested that the trough was in the region of return sunward flow where depleted plasma from the nightside was displacing dayside ionisation. The relatively low electron temperatures observed by the EISCAT radar in the current observations support this view, showing that the plasma in the trough had not been recently produced and may have circulated for some time in darkness in the absence of precipitation prior to its observation. The Universal Time of the current observations for the dayside trough spanned approximately $07: 00$ to $15: 00 \mathrm{UT}$. Whilst this interval was governed by the availability of satellite passes during the campaign, it did not overlap much with the 02:00-08:00 UT interval predicted for trough occurrence by the Utah State Model (Sojka et al., 1985).

An abrupt increase in the magnitude of the interplanetary magnetic field at the end of the quiet period led to a dramatic change in the high-latitude plasma structuring. The event started at around 06:15 UT on 27 November. The passes monitored after this time showed clearly that the ionosphere had responded to the event with a marked equatorward displacement of the trough minimum from its mean quiet-time position of about 
$71^{\circ} \mathrm{CGM}$ to $65^{\circ} \mathrm{CGM}$ by the time of the third pass. This migration to lower latitudes with increased magnetic activity was again in keeping with the observations of Whalen (1989). Interpretation of the density distributions for the passes monitored on the afternoon of this day requires consideration of the high-latitude convection pattern. The pattern is likely to be driven, at the times of the first two passes, by the effect of the strong southward IMF at the onset of the disturbance, but dominated throughout the observations by a large positive $B_{y}$ component. Comparison of the IZMEM electric potential superimposed on Fig. 7 with that for quiet times shown in Fig. 6, suggests that rotational distortion of the convection pattern has occurred as a result of the increased activity with the dayside throat region moving into the post-noon sector, although application of the model under extreme IMF conditions requires caution. This rotational distortion due to a positive $B_{y}$ component is reinforced by the flow patterns of Heppner and Maynard (1987), where the region of plasma entry into the polar cap in the $\mathrm{BC}$ pattern $\left(B_{y}>0\right.$ in the northern hemisphere) occurs at a later MLT than in the DE pattern $\left(B_{y}<0\right.$ in the northern hemisphere). This effect of $B_{y}$ on the high-latitude convection is also discussed by Cowley et al. (1991). Under the prevalent conditions of the current observations, where $B_{y}$ was extremely large and positive, it is likely that the rotational distortion was even more severe than that depicted by Heppner and Maynard (1987), and the tongue of ionisation may be entering the polar cap in the region of the satellite trajectories shown in Fig. 7. With this in mind, the following interpretation is proposed of the images presented in Fig. 8. The first image (Fig. 8a) showed two plasma regimes with the ionisation to the south and north exhibiting different peak densities and peak heights. For this pass it is believed that the equatorward sector of the trajectory intersected the solar-produced mid-latitude ionosphere while the northern region may have intersected the rotationally distorted dawn cell. The two regions of plasma to the south and north thus have very different origins and time histories, with the relatively low densities to the north being consistent with plasma convecting in the dawn cell. The similar peak densities and heights of the two features spanning the trough in the second reconstruction (Fig. 8b) suggested that they were of common origin. In this case it is proposed that the southernmost part of the trajectory was in the midlatitude regime, but the satellite-to-ground ray paths of the northern region intersected the tongue of ionisation as it wound its way into the polar cap. This interpretation can account for the large densities of the polar enhancement seen in the image and its peak height matching those of the solar-produced plasma of lower latitudes. By the time of the third satellite pass at 13:18 UT the strong positive $B_{z}$ component was well established, and may be affecting the plasma flow. However, $B_{y}$ remained large and positive and was still likely to be distorting the flow entry region into the afternoon sector. The reconstruction for this third pass showed that the height of the layer peak was again constant across the image (Fig. 8c), but the densities to the north were substantially lower than those seen at comparable latitudes during the previous pass. In this instance it is suggested that the ray paths of the trajectory in the northernmost region may have intersected the edge of the tongue of ionisation where the density values were reduced but the peak height was as for the previous pass. There was also evidence of softparticle precipitation in the northern region where the ray-path intersections were likely to be in the afternoon cell. The trajectory of the fourth pass was in the dusk region, and the corresponding image (Fig. 8d) was in complete contrast to the three images of the earlier passes. To the south was the decaying photoionisation, whilst to the north were auroral features with increased peak height within the dusk convection cell.

The electron and ion temperatures measured by the EISCAT radar provided further insight into processes occurring under these disturbed conditions. Elevated electron temperatures over an extended latitudinal range indicated soft-particle precipitation covering the region of the trough. There was not a direct correspondence between the depleted densities and elevated temperatures, with the high temperatures extending on the southern side to the equatorward density gradient of the trough. The northern extreme of the high temperatures was outside the field of view of the radar, but was clearly to the north of the trough minimum. The EISCAT ion temperatures indicated a latitudinally localised frictional heating event that started shortly after 14:00 UT. The effect of this event was to create a deep ionisation trough, apparent in the EISCAT data as lack of measured data, but observed in the tomographic image. The characteristics of this trough show similarities to those reported by Evans et al. (1983) and Holt et al. (1984), where strong electric fields and associated heating were cited to be the cause of the depleted densities.

\section{Conclusions}

Tomographic results of the northern polar ionosphere have been presented from a 2-week campaign near solar minimum. Geomagnetic conditions were extremely quiet for most of the period, but increased dramatically towards the end of the campaign. The images presented showed the contrast between the ionospheric structure under these two extremes of activity. Observations by the EISCAT radar were used to complement the tomographic images.

During the extended geomagnetically quiet period statistical results showed the expected behaviour of the night-time mid-latitude trough near the equatorward edge of the high-latitude convection flow. Of more current interest, they also showed the persistent presence of a dayside trough at higher latitudes in the region of the return plasma flow in the postnoon sector. Relatively low electron temperatures were characteristic of the latter trough. During a period of sudden increase in geomagnetic activity a marked difference was seen in plasma 
structuring, with the dayside trough being observed at lower latitudes. The response of the high-latitude ionosphere to the prevalent IMF conditions was used to interpret the different regimes observed in the reconstructed images of electron density during the active period. Temperature measurements by the EISCAT radar provided insight into the processes occurring. In particular, high electron temperatures covered the trough minimum during early afternoon passes, and high ion temperatures indicated the signature of frictional heating that gave rise to the very deep dusk-time trough.

The observations discussed here were from a campaign of limited duration. As a consequence, there were regions of the polar ionosphere that could not be investigated due to lack of suitable satellite orbits at particular times of the day. However, there is interest in these time-sectors, in particular on the dawn side where the remnants of the night-time trough may give way to the dayside trough at higher latitudes. Measurements over a longer period of time would enable a complete MLT coverage of the polar regions and would also allow observations over a range of geophysical conditions. A chain of satellite receivers for tomographic observations was installed in the autumn of 1996 for long-term routine observations, at Ny-Ålesund, Longyearbyen, Bjørnøya and Tromsø. The region covered by this chain spans between the EISCAT radar and the EISCAT Svalbard Radar (ESR). Co-ordinated observations by the two radars and the tomography receivers will serve to provide a more complete picture of the large-scale spatial structuring of the plasma in this region of the high-latitude ionosphere.

Acknowledgements. This work has been sponsored by the U.K. Particle Physics and Astronomy Research Council (PPARC) under grant GR/K98797. The co-operation of the Swedish Institute of Space Physics, the Norsk Polarinstitutt at $\mathrm{Ny}$-Ålesund and Professor T. Hansen and staff at the University of Tromsø is acknowledged. The authors are also grateful to the director and staff of the EISCAT Scientific Association. EISCAT is an international facility supported by the national science councils of Finland, France, Germany, Japan, Norway, Sweden and the United Kingdom. Thanks are also due to the EISCAT group at the Rutherford Appleton Laboratory for assistance with the development of the SP-UK-TOMO routine. MJW was funded by a PPARC research studentship.

Topical Editor D. Alcaydé thanks T. Nygren and H. Carlson for their help in evaluating this paper.

\section{References}

Austen, J. R., S. J. Franke, and C. H. Liu, Application of computerized tomography techniques to ionospheric research, in Radio Beacon contributions to the study of ionization and dynamics of the ionosphere and to corrections to geodesy and technical workshop, Ed. A. Tauriainen, pp. 25-35, Ouluensis Universitas, Oulu, Finland, 1986.

Collis, P. N., and I. Häggström, Plasma convection and auroral precipitation processes associated with the main ionospheric trough at high latitudes, J. Atmos. Terr. Phys., 50, 389-404, 1988.

Cowley, S. W. H., J. P. Morelli, and M. Lockwood, Dependence of convective flows and particle precipitation in the high-latitude dayside ionosphere on the $\mathrm{X}$ and $\mathrm{Y}$ components of the interplanetary magnetic field, J. Geophys. Res., 96, 5557-5564, 1991.

Evans, J. V., J. M. Holt, W. L. Oliver, and R. H. Wand, On the formation of daytime troughs in the F-region within the plasmasphere, Geophys. Res. Lett., 10, 405-408, 1983.

Fremouw, E. J., J. A. Secan, R. M. Bussey, and B. M. Howe, A status report on applying Discrete Inverse Theory to ionospheric tomography, Int. J. Info. Syst. Technol., 5, 97-105,1994.

Heaton, J. A. T., S. E. Pryse, and L. Kersley, Improved background representation, ionosonde input and independent verification in experimental ionospheric tomography, Ann. Geophysicae, 13, 1297-1302, 1995.

Heppner, J. P., and N. C. Maynard, Empirical high-latitude electric field models, J. Geophys. Res., 92, 4467-4489, 1987.

Holt, J. M., R. H. Wand, and J. V. Evans, Millstone Hill measurements on 26 February 1979 during the solar eclipse and formation of a midday F-region trough, J. Atmos. Terr. Phys., 46, 251-264, 1984.

Kersley, L., and S. E. Pryse, The development of experimental ionospheric tomography, Int. J. Image Syst. Technol., 5, 141147, 1994.

Mallis, M., and E. A. Essex, Diurnal and seasonal variability of the southern-hemisphere main ionospheric trough from differentialphase measurements, J. Atmos. Terr. Phys., 55, 1021-1037, 1993.

Mitchell, C. N., D. G. Jones, L. Kersley, S. E. Pryse, and I. K. Walker, Imaging of field-aligned structures in the auroral ionosphere, Ann. Geophysicae, 13, 1311-1319, 1995.

Mitchell, C. N., L. Kersley, J. A. T. Heaton, and S. E. Pryse, Determination of the vertical electron-density profile in ionospheric tomography: experimental results, Ann. Geophysicae, 15, 747-752, 1997a.

Mitchell, C. N., L. Kersley, and S. E. Pryse, The effect of receiver location in two-station experimental ionospheric tomography, J. Atmos. Terr. Phys., 59, 1411-1415, 1997 b.

Mitchell, C. N., S. E. Pryse, L. Kersley, and I. K. Walker, The correction of the satellite-receiver longitude difference in ionospheric tomography, J. Atmos. Terr. Phys., 59, 2077-2087, $1997 \mathrm{c}$.

Moffett, R. J., and S. Quegan, The mid-latitude trough in the electron concentration of the ionospheric F layer: a review of observations and modelling, J. Atmos. Terr. Phys., 45, 315-343, 1983.

Papitashvili, V. O., B. A. Belov, D. S. Faermark, Ya. I. Feldstein, S. A. Golyshev, L. I. Gromova, and A. E. Levitin, Electric potential patterns in the northern and southern polar regions parameterized by the interplanetary magnetic field, J. Geophys. Res., 99, 13251-13262, 1994.

Raymund, T. D., Comparisons of several ionospheric tomography algorithms, Ann. Geophysicae, 13, 1254-1264, 1995.

Roger, A. S., R. J. Moffett, and S. Quegan, The role of ion drift in the formation of the ionisation troughs in the mid- and highlatitude ionosphere - a review, J. Atmos. Terr. Phys., 54, 1-30, 1992.

Sojka, J. J., W. J. Raitt, R. W. Schunk, J. L. Parish, and F. J. Rich, Diurnal variation of the dayside, ionospheric mid-latitude trough in the southern hemisphere at $800 \mathrm{~km}$ : model and measurement comparison, Planet. Space Sci., 33, 1375-1382, 1985.

Tulunay, Y. K., and J. M. Grebowsky, The noon and midnight midlatitude trough as seen by Ariel 4, J. Atmos. Terr. Phys., 40, 845-855, 1978.

Walker, I. K., J. A. T. Heaton, L. Kersley, C. N. Mitchell, S. E. Pryse, and M. J. Williams, EISCAT verification in the development of ionospheric tomography, Ann. Geophysicae, 14, 1413-1421, 1996.

Whalen, J. A., Daytime F layer trough observed on a macroscopic scale, J. Geophys. Res., 92, 2571-2576, 1987.

Whalen, J. A., The daytime F layer trough and its relation to ionospheric-magnetospheric convection, J. Geophys. Res., 94, 17169-17184, 1989. 